\title{
VAlidation OF A High-Order Prefactored COMPACT CODE ON NONLINEAR FLOWS WITH COMPLEX GEOMETRIES
}

\author{
R. Hixon \\ University of Toledo \\ Toledo, $\mathrm{OH} 43606$ \\ R. R. Mankbadi \\ Embry-Riddle Aeronautical University \\ Daytona Beach, FL 32114 \\ J. R. Scott \\ NASA Glenn Research Center \\ Cleveland, $\mathrm{OH} 44135$
}

\begin{abstract}
A finite-difference time domain solution of the airfoil gust problem is obtained using a high-accuracy nonlinear computational aeroacoustics code. For computational efficiency, the equations are cast in chain-rule curvilinear form, and a structured multiblock solver is used in parallel. In order to fully investigate the performance of this solver, a test matrix of eight problems are computed (two airfoil geometries, two gust frequencies, and two gust configurations). These results are compared to solutions obtained by the GUST3D frequency-domain solver both on the airfoil surface and in the far field. Grid density and domain size studies are included.
\end{abstract}




\section{Introduction}

Computational aeroacoustics (CAA) is concerned with the time-accurate solution of flow and acoustic phenomena over long periods of time. In the problems of interest, the flow has a range of length and time scales, and bodies with complex geometry are in the computational domain. To accurately compute these unsteady problems, high-order finite-difference schemes and optimized schemes have been developed, as well as highaccuracy boundary conditions. For an overview of the CAA field, the reader is referred to two excellent review papers ${ }^{1,2}$.

One problem of interest is the noise radiated when a vortical gust impinges on an airfoil with realistic geometry. This problem appears in helicopter noise as well as in turbomachinery noise. In the past, this problem has been solved numerically by finitedifference frequency-domain solvers by Scott and Atassi ${ }^{3,4}$. In the time domain, it has been solved for flat plates using linearized potential by Hariharan et. $a l^{5}$, using the linearized Euler equations by Tam et. al. ${ }^{6}$, and using full nonlinear Euler equations by Lockard and Morris ${ }^{7}$. The nonlinear Euler work of Lockard and Morris has also been extended to NACA 0006 and 0012 airfoil geometries, both lifting and nonlifting ${ }^{8}$.

In past work, the gust response of two Joukowski airfoil geometries has been computed and compared to the GUST3D solutions using the NASA GRC PFC6 code. ${ }^{9,10}$ The ability of the PFC6 solver to accurately capture the pressure disturbance distribution on the airfoil surface has been demonstrated in that work.

The present work is a more in-depth investigation of the performance of the PFC6 code, comparing results from the near- and far-field as well as on the airfoil surface. The results show the ability of the code to accurately predict surface as well as far-field noise 
radiation. Grid density and domain studies show the effects of the boundary conditions and grid spacing on the solution obtained.

\section{Mathematical and Numerical Formulation}

In this work, the 2-D nonlinear Euler equations are solved. In Cartesian coordinates these equations are written as:

$$
\frac{\partial Q}{\partial t}+\frac{\partial E}{\partial x}+\frac{\partial F}{\partial y}=0
$$

where

$$
\begin{gathered}
Q=\left\{\begin{array}{c}
\rho \\
\rho u \\
\rho v \\
E
\end{array}\right\} \\
E=\left\{\begin{array}{c}
\rho u \\
\rho u^{2}+p \\
\rho u v \\
u(E+p)
\end{array}\right\} \\
F=\left\{\begin{array}{c}
\rho v \\
\rho u v \\
\rho v^{2}+p \\
v(E+p)
\end{array}\right\}
\end{gathered}
$$


and

$$
p=(\gamma-1)\left(E-\frac{1}{2} \rho\left(u^{2}+v^{2}\right)\right)
$$

Since the Joukowski airfoil has a complex geometry that does not lend itself to Cartesian grids, the equations were recast in generalized curvilinear coordinates. From previous numerical tests ${ }^{11}$, the chain-rule formulation was chosen as the most accurate form of the equations. The chain-rule curvilinear Euler equations are written as:

$$
\frac{\partial Q}{\partial t}+\xi_{x}\left(\frac{\partial E}{\partial \xi}\right)+\xi_{y}\left(\frac{\partial F}{\partial \xi}\right)+\eta_{x}\left(\frac{\partial E}{\partial \eta}\right)+\eta_{y}\left(\frac{\partial F}{\partial \eta}\right)=0
$$

The code used in this work was the NASA GRC PreFactored Compact 6 (PFC6) code, which is a predecessor to the current NASA GRC BASS code. The time stepping method used by PFC6 was the low storage fourth-order nonlinear extension of Hu's 5-6 Low Dispersion and Dissipation Runge-Kutta scheme ${ }^{12}$ by Stanescu and Habashi ${ }^{13}$.

The spatial derivatives are calculated using the prefactored sixth-order compact scheme and explicit boundary stencils of Hixon. ${ }^{14}$ At block boundaries, an 11- point explicit stencil was used. A 10 th order explicit filter ${ }^{15}$ was used at every stage of the Runge-Kutta solver to provide dissipation. The code is written in Fortran 90 to take advantage of the improved memory management and data structures of Fortran 90 as compared to Fortran 77. This scheme and code has been extensively validated on benchmark problems, performing very well (e.g., Refs. 9,10,14,16-18,21). 
The grid used employed a C-grid topology (Figure 1), extending at least five chord lengths away from the airfoil in each direction. Several tests were conducted for larger domains which extended 10 and 20 chord lengths away. The smallest grid was $433 \times 125$ (54125 total) points, with the middle grid being $605 \times 240$ (145200 total) points, and the largest grid having $790 \times 271$ (214090 total) points. All grids were generated using the commercial package GridPro $^{19}$. The grid was clustered algebraically in the normal direction $(\Delta \mathrm{n}=0.01)$ and near the trailing edge point $(\Delta \mathrm{x}=0.01)$, as shown in Fig. 2. A stretching ratio of 1.05 was used to a far-field spacing of $\Delta x=\Delta y=0.106$. This spacing gave a minimum of 15 points per gust wavelength. While this is far more than the six points per wavelength that the scheme could use on a uniform Cartesian grid, the dense grid was used to ensure that resolution problems would be minimized for this test.

For the calculation, the grid was generated as a single block and the domain was distributed by the code for parallel computations on an arbitrary number of processors. For this $2 \mathrm{D}$ test case, tests on both a cluster of SGI Octane workstations as well as on a cluster of Apple Power Macintosh G4/450 machines showed excellent parallel performance for up to 15 machines.

\section{Problem Description}

In this set of problems, a simple-harmonic vortical gust convects past a $12 \%$ thick Joukowski airfoil. The gust has the distribution: 


$$
\begin{aligned}
& u_{\text {gust }}=-\left(\frac{\varepsilon \beta M}{\sqrt{\alpha^{2}+\beta^{2}}}\right) \cos (\alpha x+\beta y-\omega t) \\
& v_{\text {gust }}=\left(\frac{\varepsilon \alpha M}{\sqrt{\alpha^{2}+\beta^{2}}}\right) \cos (\alpha x+\beta y-\omega t)
\end{aligned}
$$

Here, $\varepsilon=0.02$.

Two gust configurations were tested. The first was a transverse gust:

$$
\begin{aligned}
& \alpha=2 k \\
& \beta=0 \\
& \omega=2 k M
\end{aligned}
$$

and the second was a two-dimensional gust:

$$
\begin{aligned}
& \alpha=2 k \\
& \beta=2 k \\
& \omega=2 k M
\end{aligned}
$$

where $\mathrm{M}$ is the freestream Mach number.

For each gust distribution, two reduced frequencies were tested: $\mathrm{k}=0.1$, and $\mathrm{k}=1.0$. Figures 3 and 4 show instantaneous v-velocity distributions for the cambered airfoil cases at $\mathrm{k}=1.0$, while Figures 5 and 6 show the instantaneous pressure distributions for those 
cases. Note that the two-dimensional gust propagates at a $45^{\circ}$ angle to the airfoil. Note also the clean boundary treatments and lack of reflections for both vortical and acoustic waves.

The mean flow at infinity is defined as:

$$
\begin{aligned}
\bar{\rho} & =1.0 \\
\bar{u} & =M \\
\bar{v} & =0 \\
\bar{p} & =\frac{1}{\gamma}(\bar{\rho})^{\gamma}
\end{aligned}
$$

where $\mathrm{M}=0.5$ and $\gamma=1.4$.

Two airfoil geometries are tested in this work. The first geometry is a symmetric airfoil at a zero degree angle of attack. The second geometry is a cambered airfoil (camber ratio $=0.02$ ) at a two-degree angle of attack.

\section{Initial and Boundary Conditions}

For both cases the flow was initialized to the mean flow with the vortical gust superposed: 


$$
\begin{aligned}
& \rho(x, y, 0)=\bar{\rho} \\
& u(x, y, 0)=\bar{u}+u_{\text {gust }}(x, y, 0) \\
& v(x, y, 0)=\bar{v}+v_{\text {gust }}(x, y, 0) \\
& p(x, y, 0)=\bar{p}
\end{aligned}
$$

At the wall, Hixon's inviscid curvilinear wall boundary condition ${ }^{20}$ was used, modified to set the normal momentum to zero at the wall at each Runge-Kutta stage.

At the inflow boundary, the acoustic radiation condition of Tam and $\mathrm{Webb}^{21}$ was used on the outgoing perturbations. For example, the outgoing u-velocity perturbation $u_{B C}$ was defined as:

$$
u_{B C}=u_{\text {boundary }}-\bar{u}-u_{\text {gust }}
$$

At the outflow boundary, Tam and Webb's radiation outflow condition ${ }^{21}$ was used with no correction for the outgoing vortical gust.

At the trailing edge point on the airfoil, the C-grid topology defines the airfoil geometry incorrectly, causing numerical inaccuracy. While an O-grid geometry would define the trailing edge geometry properly, the $\mathrm{C}$ - grid was chosen due to the excessive number of grid points and the associated small time steps that the $\mathrm{O}$ - grid would require to accurately resolve the sharp trailing edge.

At the trailing edge, an upper and lower wall condition is calculated; this makes the trailing edge point double-valued. The wake is single-valued, however; the upper wake block is allowed to set the wake line. The discontinuity in the boundary condition on the surface line as it enters the wake causes a loss of accuracy near the trailing edge, which is 
especially apparent for the lifting, high-frequency results. To reduce the effect on the global solution, points were clustered near the trailing edge as shown in Figure 2. Figure 7 shows the effect of the discontinuity on the pressure contours near the trailing edge of the cambered airfoil. The effect was much stronger on the cambered lifting airfoil than on the symmetric nonlifting airfoil.

\section{$\underline{\text { 5. Results }}$}

The PFC6 code was run until the lift coefficient settled to a simple harmonic state, corresponding to a nondimensional time of 210 , requiring 55 hours using the largest grid on a 15-processor Macintosh G4/450 cluster. Later optimization of the code reduced this time to 19 hours. As expected, the nonlifting airfoil case converged faster; the lifting airfoil case results were still changing very slightly from one period of gust oscillation to the next. A time step of $\mathrm{CFL}=1.5$ was used for all calculations, giving approximately 911 time steps per cycle of vorticity for the $k=1.0$ case and 9110 time steps per cycle of vorticity for the $\mathrm{k}=0.1$ case on the smallest grid.

The mean pressures on the airfoil for the 2-D gust cases are shown in Figure 8, compared to FLO36 results ${ }^{22}$. The effect of the trailing edge condition is apparent in both figures; however, the effect is localized near the trailing edge. In both figures, some oscillations are seen near the peak of the pressure curve; this is due to the high gradients in both the flow properties and the changes in grid spacing near the leading edge. However, the effect on the mean solution is minimal. It is seen that the lifting airfoil peak 
pressures are consistently overpredicted; studies found that enlarging the computational domain caused the predicted lift to decrease.

Figures 9 and 10 show the RMS pressure disturbance distribution on the airfoil. Again, some oscillations can be seen near the peaks of the pressure disturbance, but these were found to have little effect on the solution. The trailing edge condition has some effect on the solution on the airfoil, particularly for the high- frequency gusts. However, as shown in Figures 9 and 10, the code is predicting the changing pressure distributions for all eight test cases very well, accurately capturing the effects of airfoil geometry, gust geometry, and gust frequency.

Figures 11 and 12 show the acoustic intensity at a distance of one chord length away from the centerpoint of the airfoil. Here the comparison is very good for the lowfrequency cases and still good for the high-frequency cases. Notice that the agreement is better for the nonlifting cases than for the loaded airfoils; however, all comparisons are very acceptable.

Figures 13 and 14 show the acoustic intensity at a distance of four chord lengths away from the centerpoint of the airfoil. The GUST3D solution at this location was obtained using a Kirchhoff approach. ${ }^{23}$ The Kirchhoff surface was a circle of radius two chord lengths, centered about the airfoil center. Again, the comparisons are very good for the low-frequency cases, and the high-frequency results are acceptable. 


\section{Grid Density and Domain Size Studies}

Two solution convergence studies were performed in this work. In the first study, the effect of grid density on the solution was tested for the low-frequency, 1D gust case on the cambered airfoil. A dense grid was generated which contained $677 \times 233$ points (157741 total points), but still using the small domain (5 chord lengths to the outer boundary). In this way, the effect of both clustering more grid points at the high-gradient leading edge region and increasing the number of grid points per wavelength could be determined. As Figure 15 illustrates, there was very little difference in the computed solutions for both grid densities. Thus, all other cases were run using grids closely resembling the small- domain grid near the airfoil.

The next study focused on the effect of the boundary proximity to the airfoil. For the cambered, lifting airfoil case in particular, the distance to the far-field boundary condition had a large effect on the computed results. Figures 16-18 show the effect of increasing domain size on the acoustic intensity results at one chord length away from the airfoil, with the domain boundaries ranging from 5 to 20 chord lengths away from the airfoil. It was found during these numerical investigations that the outer boundary effect was minimal on the near-field solution as long as the outer boundary was located at least 10 chord lengths away from the airfoil. 


\section{Conclusions}

A test matrix of eight gust-airfoil interaction problems were solved using a parallelized prefactored sixth- order compact scheme with 10th order filtering, run on distributed computer clusters. These problems tested the accuracy of the code on stretched, curvilinear grids with nonlinear flows. In all cases, the code was robust and converged well. In these tests, the code predicted the trends and magnitudes of the airfoil gust response very well for the eight test cases, while showing some effect from the boundary condition reflections and the close proximity of the computational boundaries. The effect of larger domain sizes was investigated, and it was found that the near-field solution became invariant once the domain boundary was at least 10 chord lengths away from the airfoil. A grid density study was also performed, and it was found that the solution was effectively grid-independent for these calculations.

\section{Acknowledgment}

This work was carried out under grant NCC3-781 from the NASA Glenn Research Center. Dennis Huff was the Technical Monitor. 


\section{$\underline{\text { References }}$}

1) Tam, C. K. W., 'Computational Aeroacoustics: Issues and Methods', AIAA J., Vol. 33, 1995, pp. 1788-1796.

2) Lele, S. K., 'Computational Aeroacoustics: A Review', AIAA Paper 97-0018, Jan. 1997.

3) Scott, J. R. and Atassi, H. M., 'Numerical Solutions of the Linearized Euler Equations for Unsteady Vortical Flows Around Lifting Airfoils', AIAA Paper 90-0694, Jan. 1990.

4) Scott, J. R., and Atassi, H. M., 'A Finite-Difference, Frequency-Domain Numerical Scheme for the Solution of the Gust-Response Problem', Journal of Computational Physics, Vol. 119, 1995, p. 75-93.

5) Hariharan, S. I., Ping, Y., and Scott, J. R., 'Time Domain Numerical Calculations of Unsteady Vortical Flows about a Flat Plate Airfoil', Journal of Computational Physics, Vol. 101, No. 2, Aug. 1992, pp. 419-430.

6) Tam, C. K. W., Fang, J., and Kurbatskii, K. A., 'Non-Homogeneous Radiation and Outflow Boundary Conditions Simulating Incoming Acoustic and Vorticity Waves for Exterior Computational Aeroacoustics Problems', International Journal for Numerical Methods in Fluids, Vol. 26, 1998, pp. 1107-1123.

7) Lockard, D. P. and Morris, P. J., 'A Parallel Implementation of a Computational Aeroacoustic Algorithm for Airfoil Noise', AIAA Paper 96-1754, 1996.

8) Lockard, D. P. and Morris, P. J., 'The Radiated Noise from Airfoils in Realistic Mean Flows', AIAA Paper 97-0286, Jan. 1997. 
9) Hixon, R., Shih, S.-H., Mankbadi, R. R., and Scott, J. R., 'Time Domain Solution of the Airfoil Gust Problem Using a High-Order Compact Scheme', AIAA Paper 98-3241, Cleveland, OH, July 1998.

10) Hixon, R. and Mankbadi, R. R., 'Validation of a High-Order Prefactored Compact Scheme on Nonlinear Flows with Complex Geometries', Third Computational Aeroacoustics (CAA) Workshop on Benchmark Problems, NASA CP-2000-209790, August 2000, p. 117-132.

11) Hixon, R., Shih, S.-H., Dong, T., and Mankbadi, R. R., 'Evaluation of Generalized Curvilinear Coordinate Transformations Applied to High-Accuracy Finite-Difference Schemes', AIAA Paper 98-0370, Jan. 1998.

12) Hu., F. Q., Hussaini, M. Y., and Manthey, J. L., 'Low-Dissipation and LowDispersion Runge-Kutta Schemes for Computational Acoustics', Journal of Computational Physics, Vol. 124, No. 1, 1996, pp. 177-191.

13) Stanescu, D. and Habashi, W. G., '2N-Storage Low Dissipation and Dispersion Runge- Kutta Schemes for Computational Acoustics', Journal of Computational Physics, Vol. 143, No. 2, 1998, p. 674-681.

14) Hixon, R., 'Prefactored Small-Stencil Compact Schemes', Journal of Computational Physics, Vol. 165, 2000, p. 522-541.

15) Kennedy, C. A. and Carpenter, M. H., 'Several New Numerical Methods for Compressible Shear-Layer Simulations', Applied Numerical Mathematics, Vol. 14,1994, pp. 397-433. 
16) Hixon, R., Shih, S.-H., and Mankbadi, R. R., 'Evaluation of Boundary Conditions for the Gust-Cascade Problem', Journal of Propulsion and Power, Vol. 16, No. 1, 2000, pp. 72- 78.

17) Hixon, R., Shih, S.-H., and Mankbadi, R. R., 'Numerical Treatment of Cylindrical Coordinate Centerline Singularities', AIAA Paper 99-2391, Los Angeles, CA, June 1999.

18) Hixon, R., 'Numerically Consistent Strong Conservation Grid Motion for Finite-Difference Schemes', AIAA Journal, Vol. 38, No. 9, 2000, p. 1586-1593.

19) GridPro ${ }^{\mathrm{TM}} / \mathrm{az} 3000$, Program Development Corporation, White Plains, NY, 1996.

20) Hixon, R., 'Curvilinear Wall Boundary Conditions for Computational Aeroacoustics', AIAA Paper 99-2395, Los Angeles, CA, June 1999.

21) Tam, C. K. W. and Webb, J. C., 'Dispersion-Relation-Preserving Finite Difference Schemes for Computational Acoustics', Journal of Computational Physics, Vol. 107, 1993, p. 262-281.

22) Jameson, A. and Caughey, D. A., 'A Finite Volume Method for Transonic Potential Flow Calculations', Proceedings of the AIAA 3rd Computational Fluid Dynamics Conference, Williamsburg, VA, July 1979, pp. 122-146.

23) Hariharan, S. I., Scott, J. R., and Krieder, K. L., 'A Potential-Theoretic Method for Far-Field Sound Radiation Calculations', Journal of Computational Physics, Vol. 164, 2000, p. 143-164. 


\section{Figures}

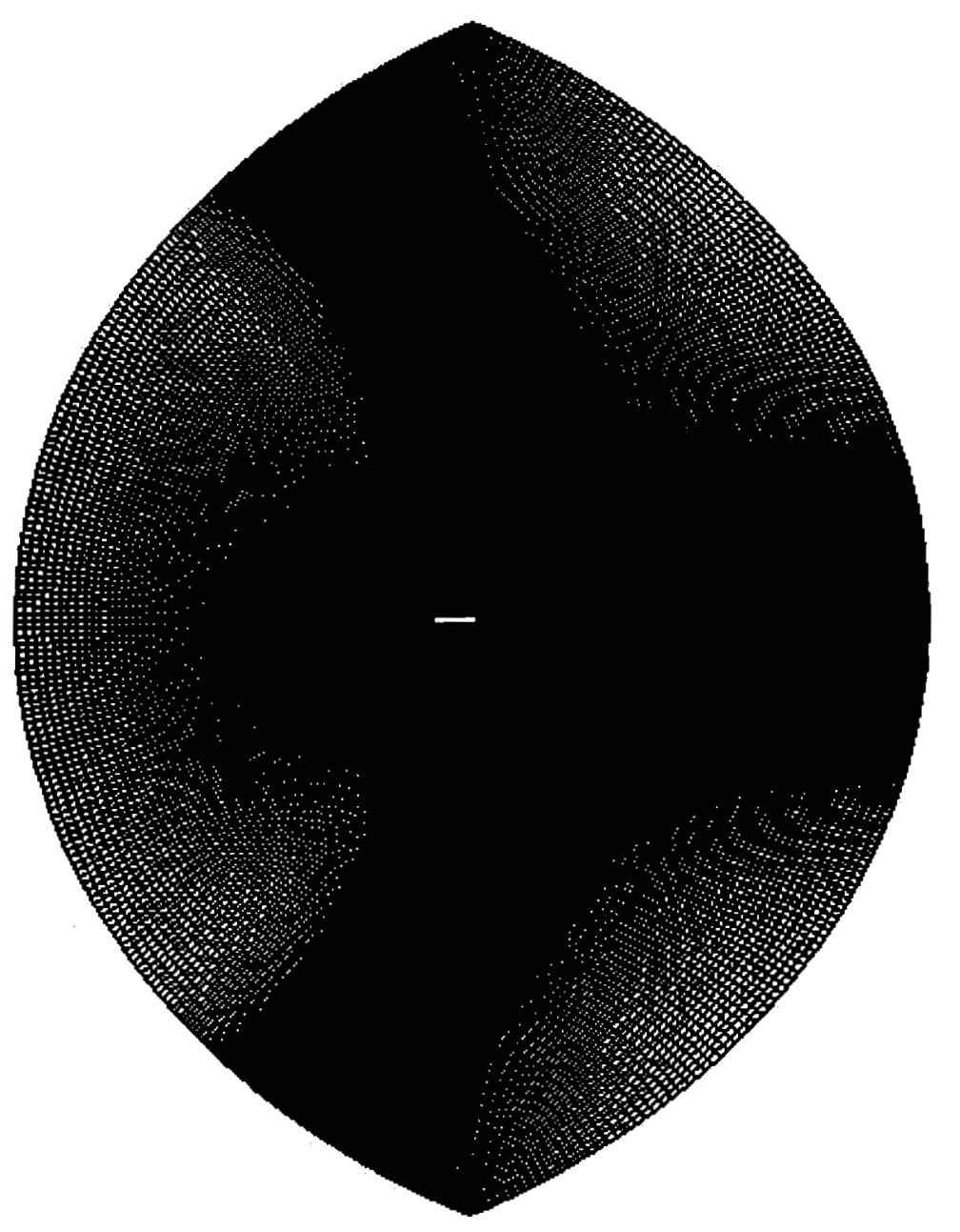

Figure 1: C-Grid Used for Joukowski Airfoil (433 x 125) 


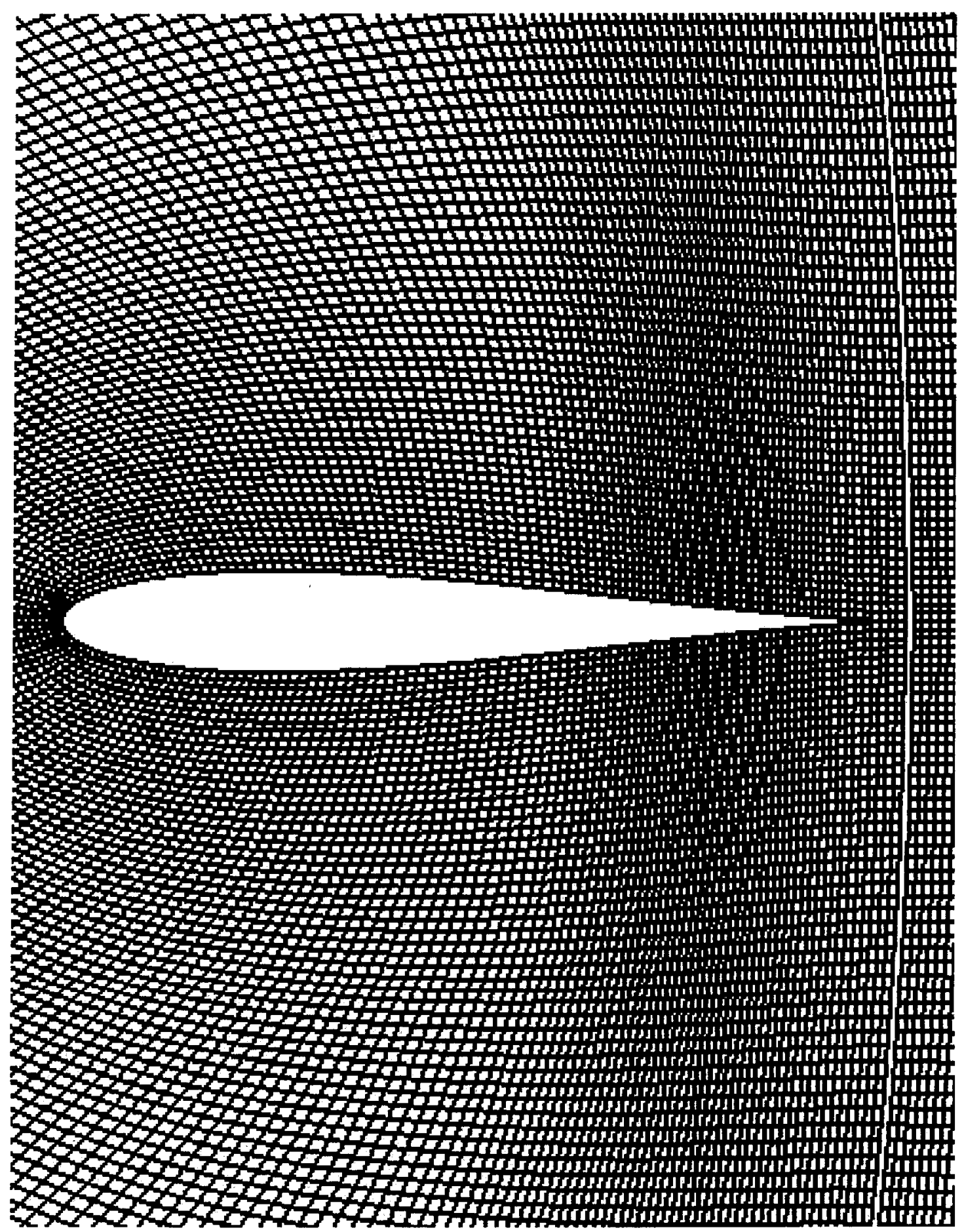

Figure 2: Closeup of Symmetric Airfoil Grid 


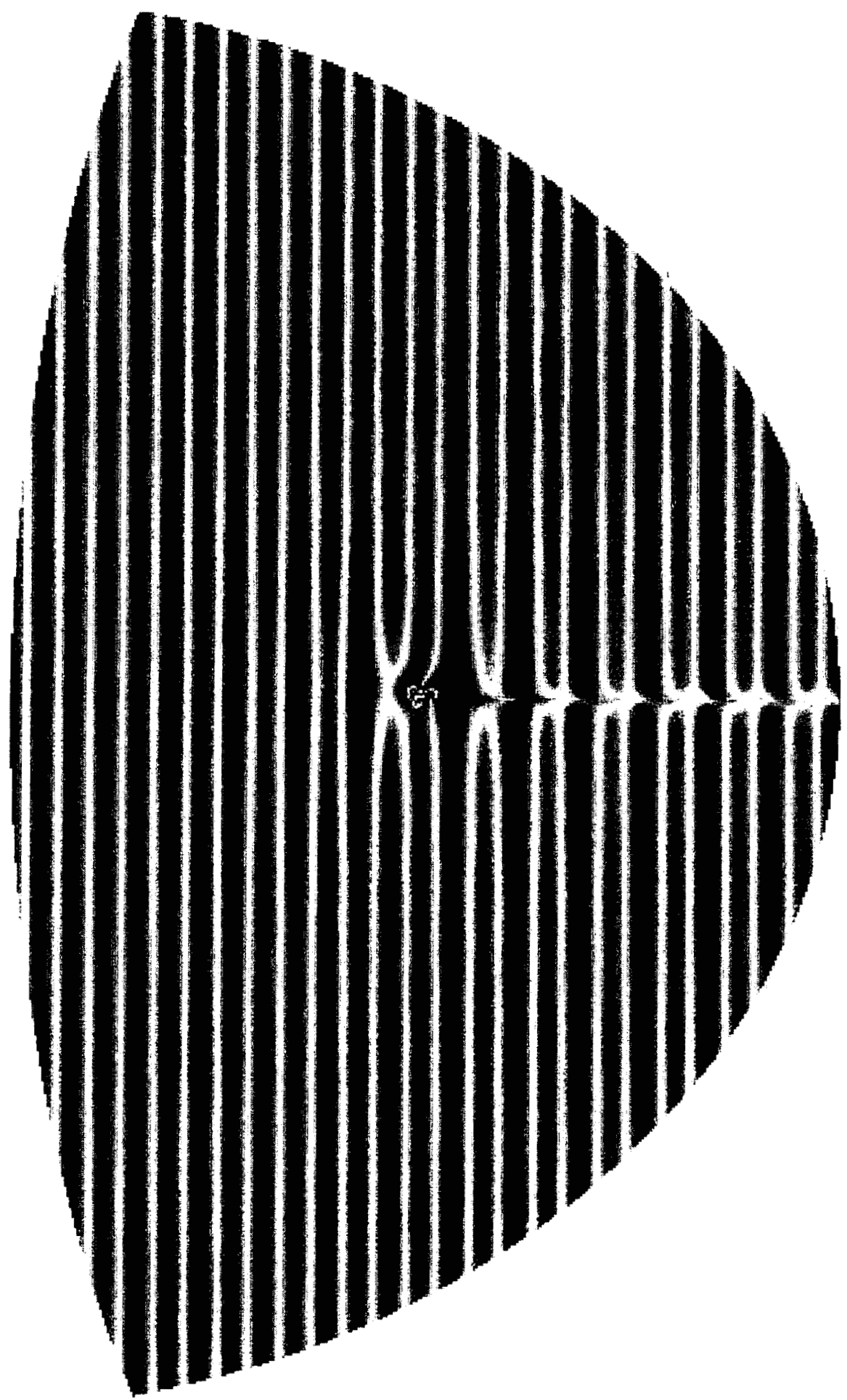

Figure 3: Instantaneous V Velocity Distribution ( $k=1.0,1 D$ gust, cambered airfoil) 


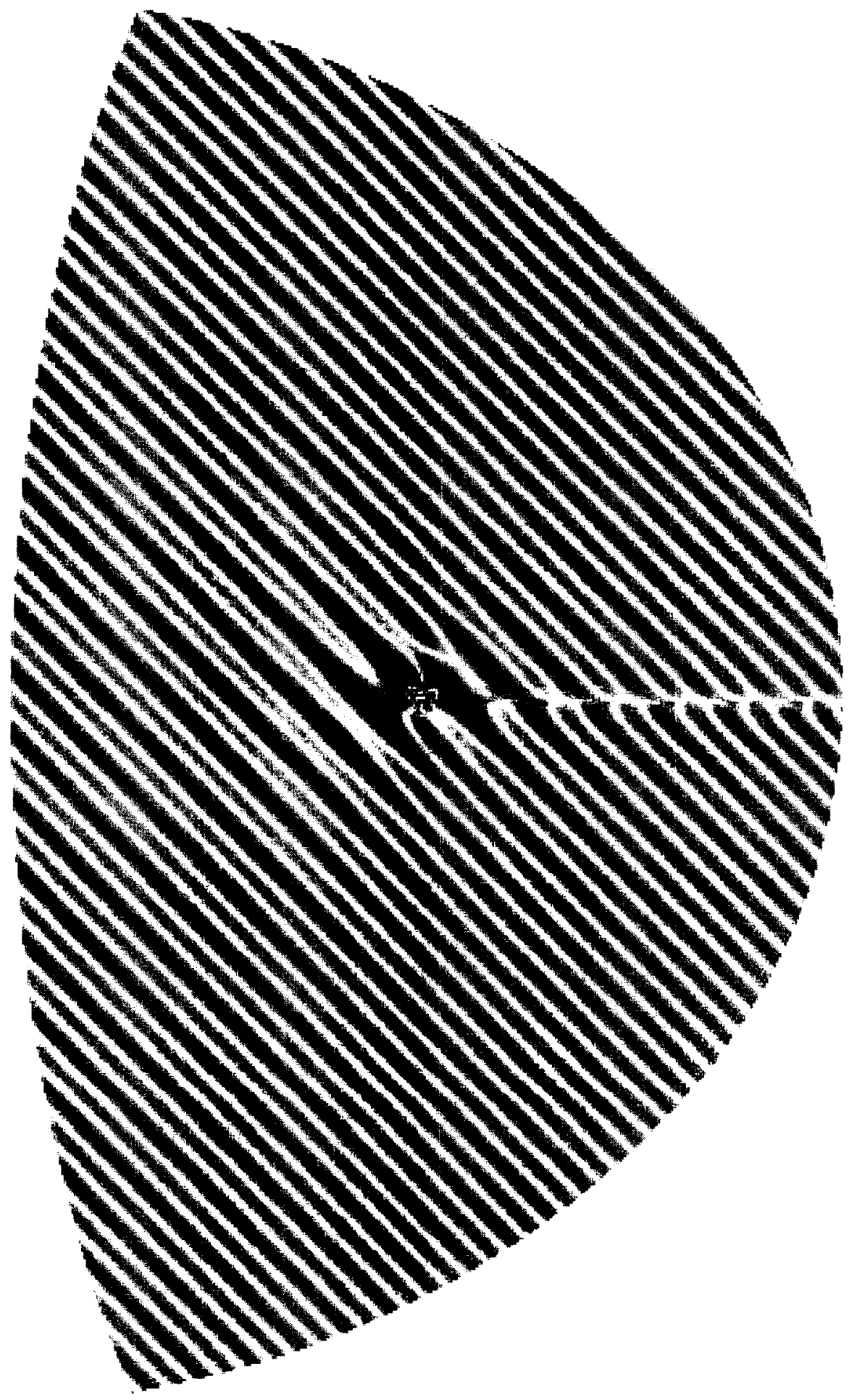

Figure 4: Instantaneous V Velocity Distribution

$$
\text { ( } k=1.0,2 D \text { gust, cambered airfoil) }
$$




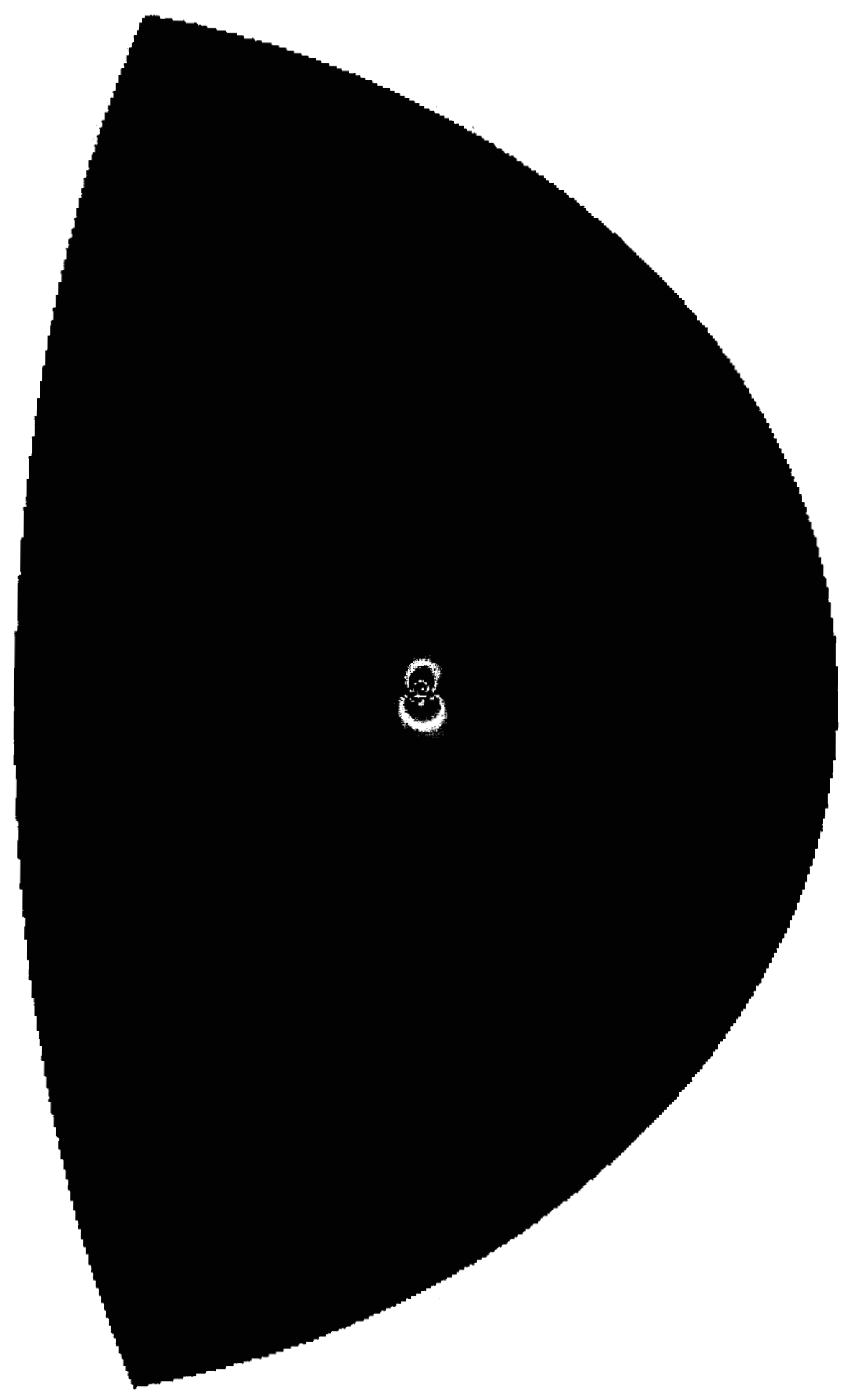

Figure 5: Instantaneous Pressure Distribution

$(k=1.0,1 D$ gust, cambered airfoil) 


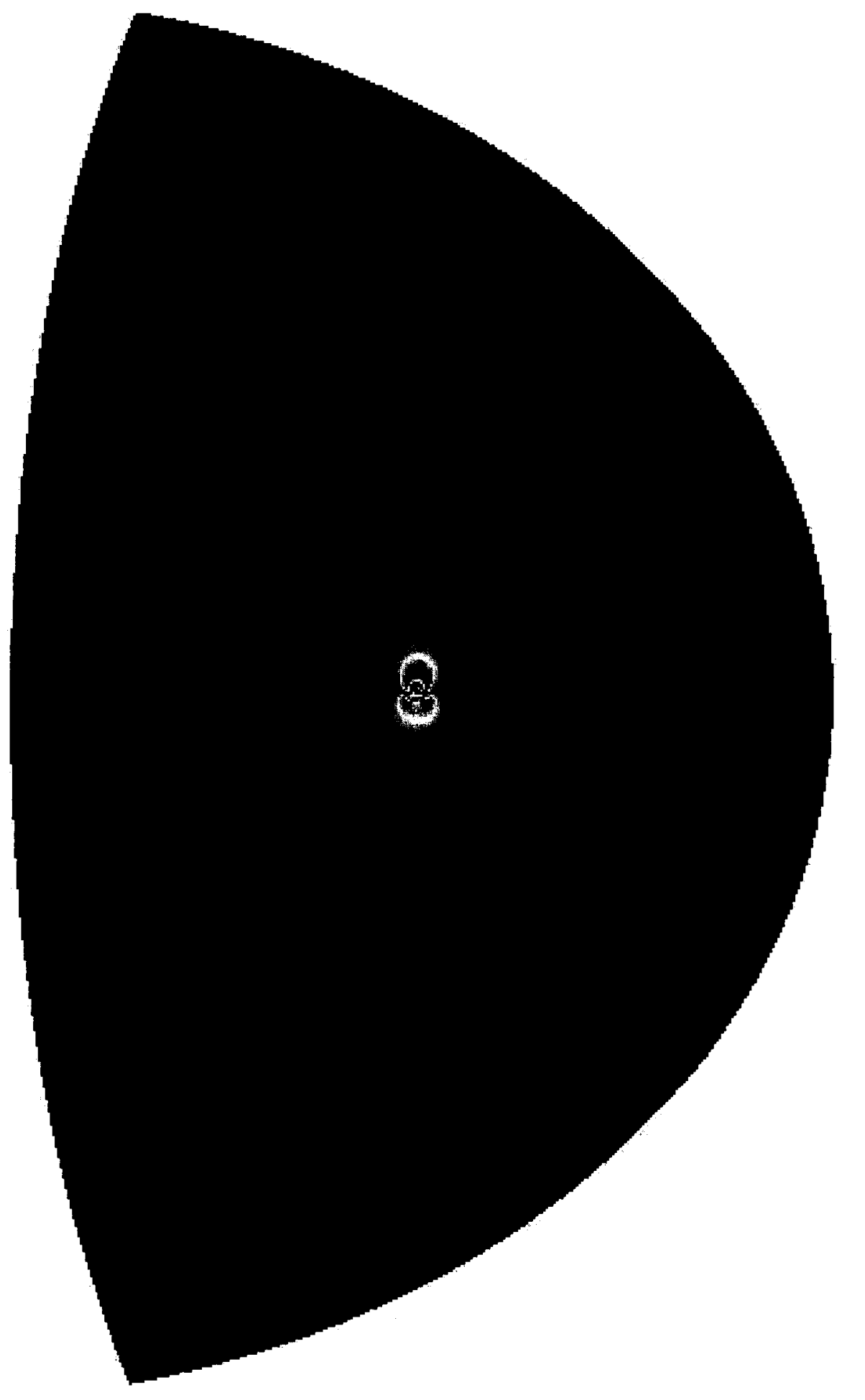

Figure 6: Instantaneous Pressure Distribution

( $k=1.0,2 \mathrm{D}$ gust, cambered airfoil $)$ 


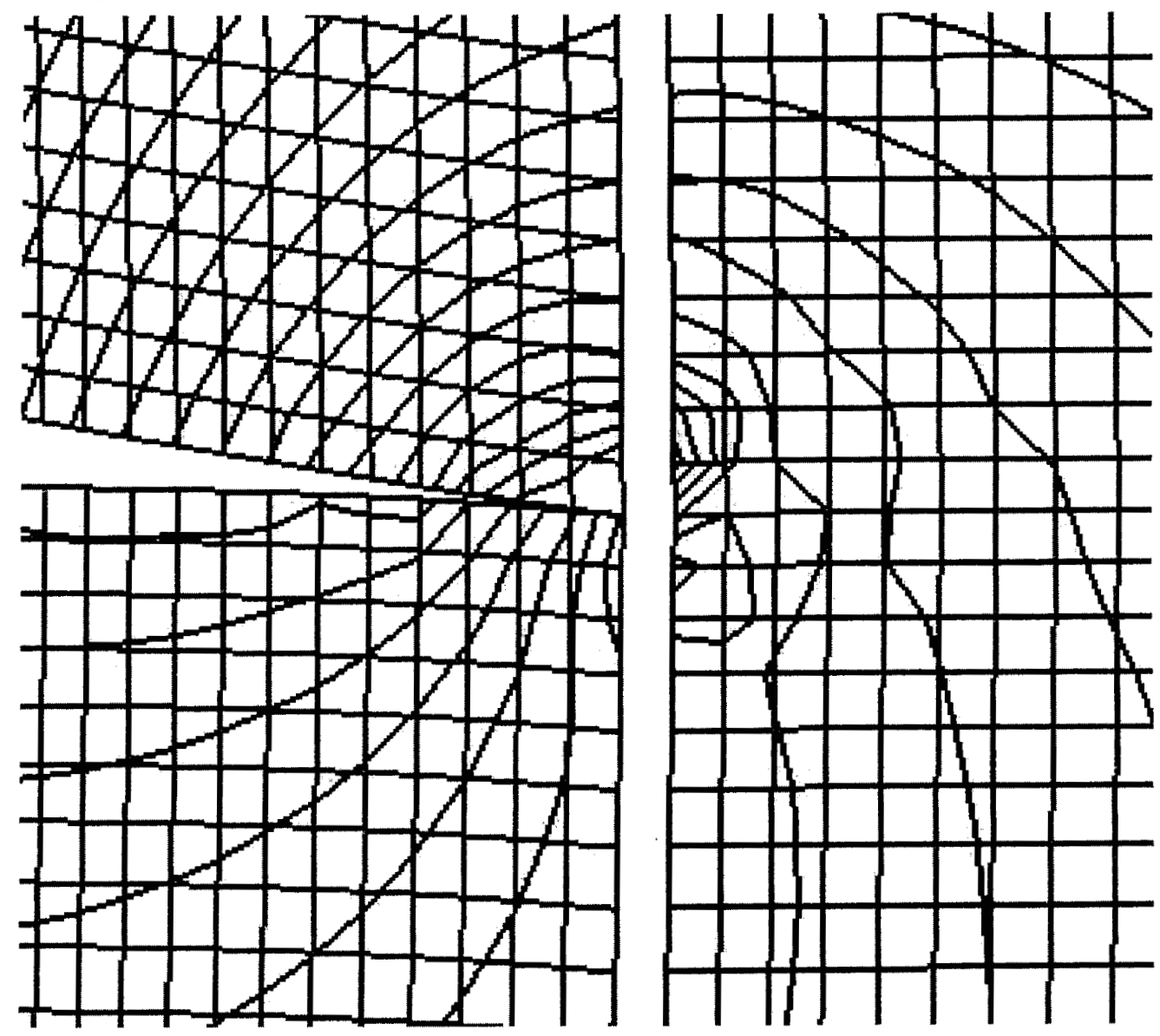

Figure 7: Effect of Trailing Edge Grid Singularity on Instantaneous Pressure Contours for Cambered Airfoil 


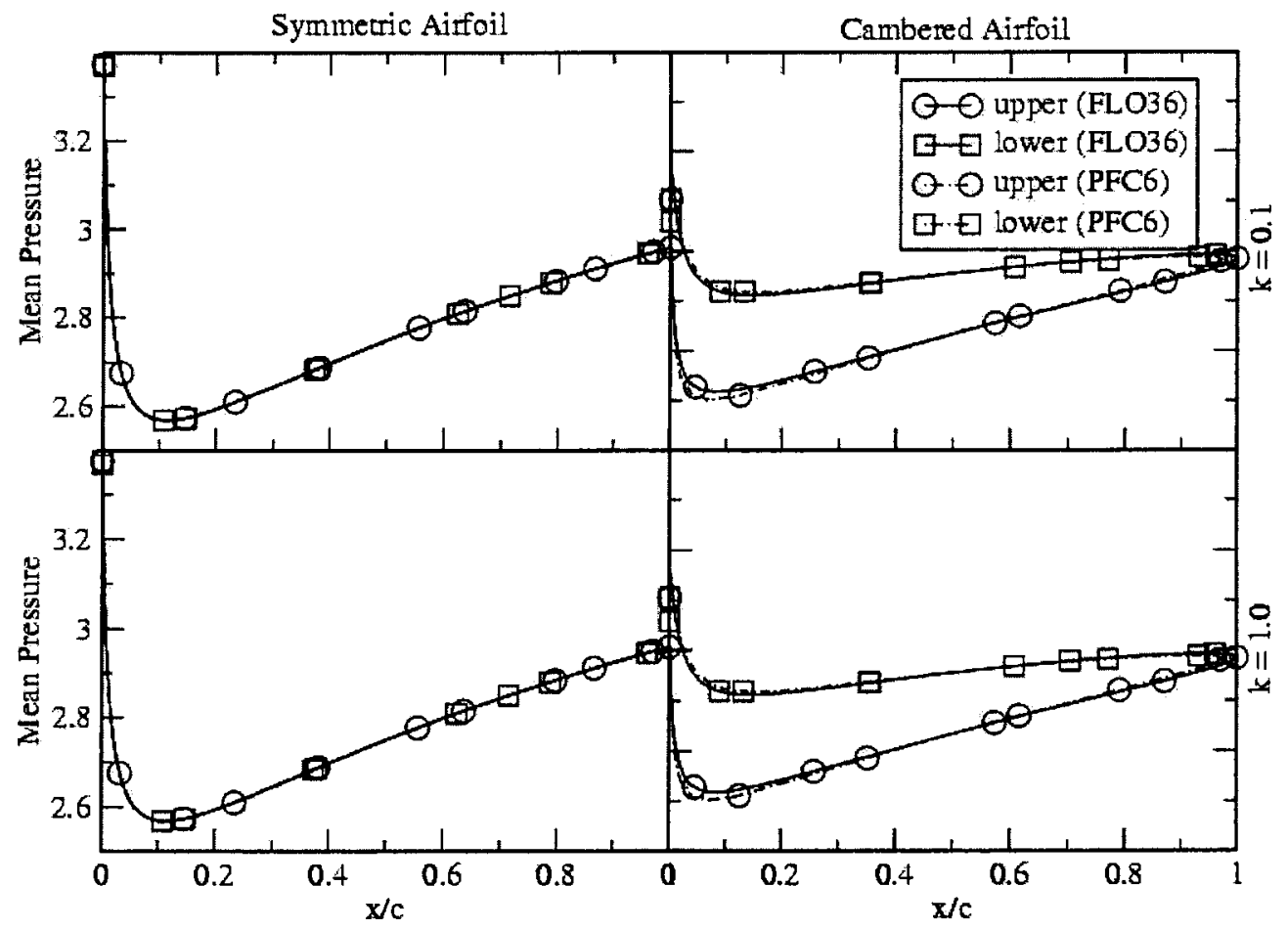

Figure 8: Mean Pressure Distribution on the Airfoil Surface 


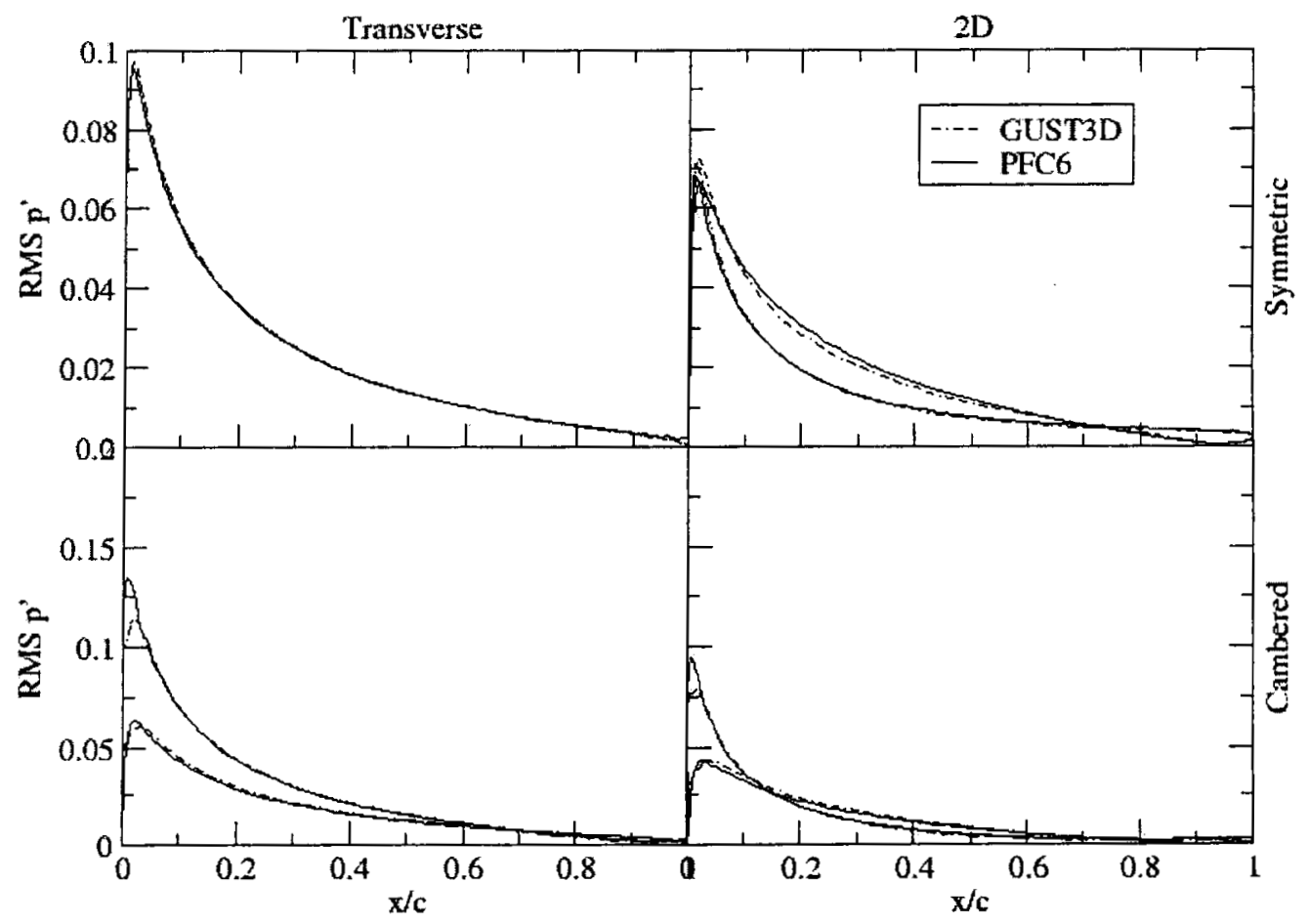

Figure 9: RMS Pressure Disturbance Distribution on the Airfoil Surface

$$
(\mathbf{k}=\mathbf{0 . 1})
$$




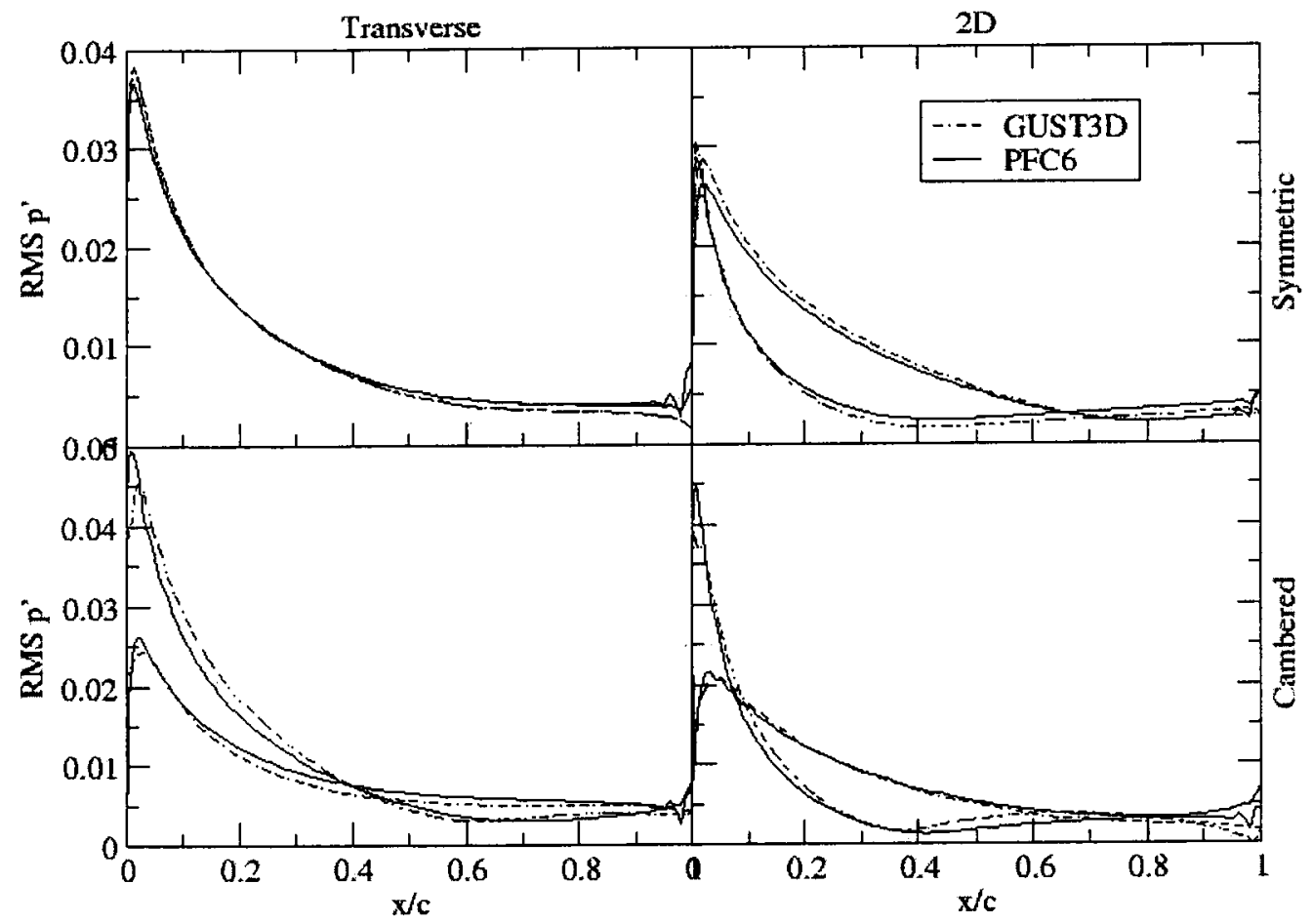

Figure 10: RMS Pressure Disturbance Distribution on the Airfoil Surface

$$
(\mathrm{k}=\mathbf{1 . 0})
$$




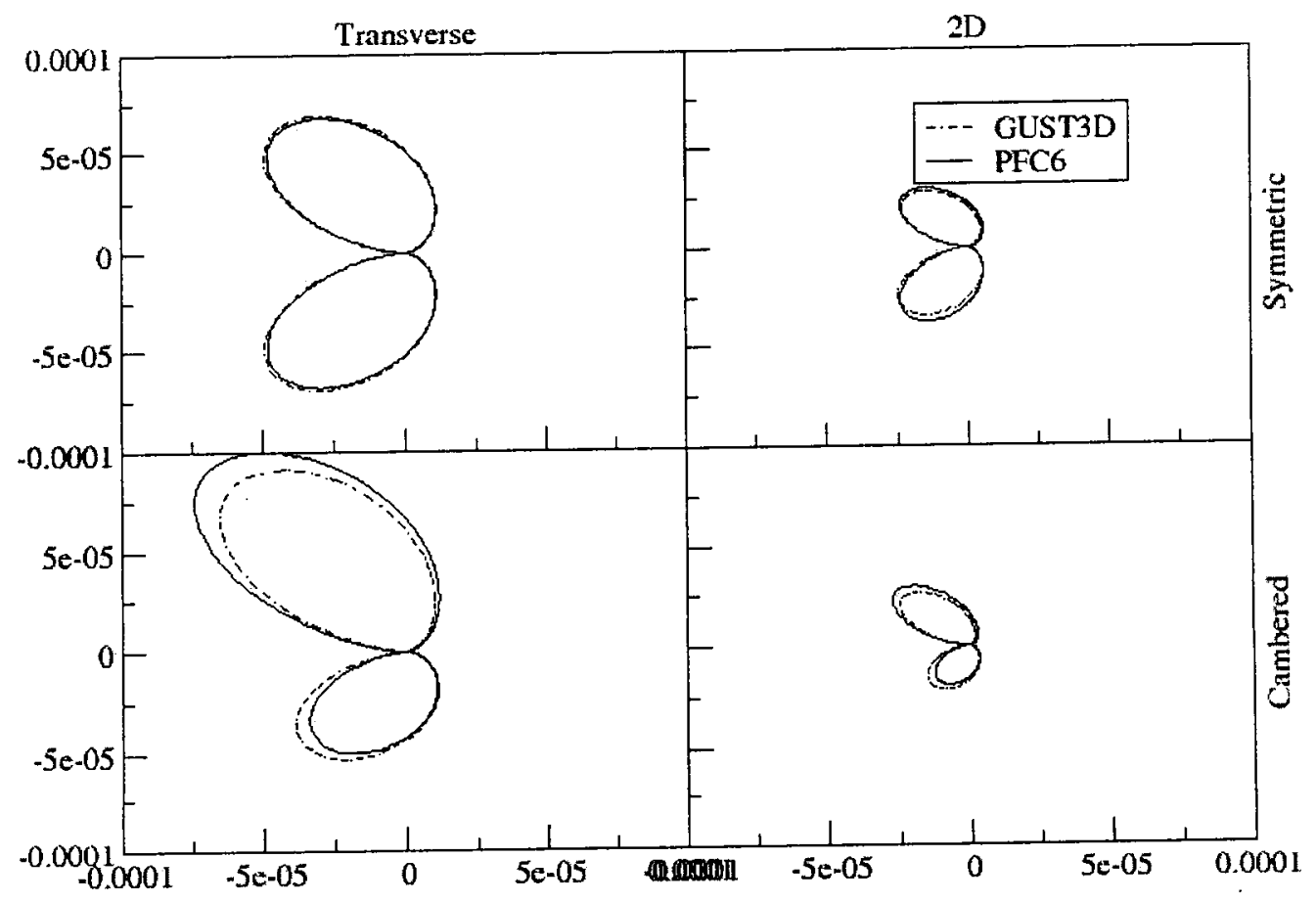

Figure 11: Acoustic Intensity Distribution at $R=1.0$

$$
(\mathbf{k}=\mathbf{0 . 1})
$$




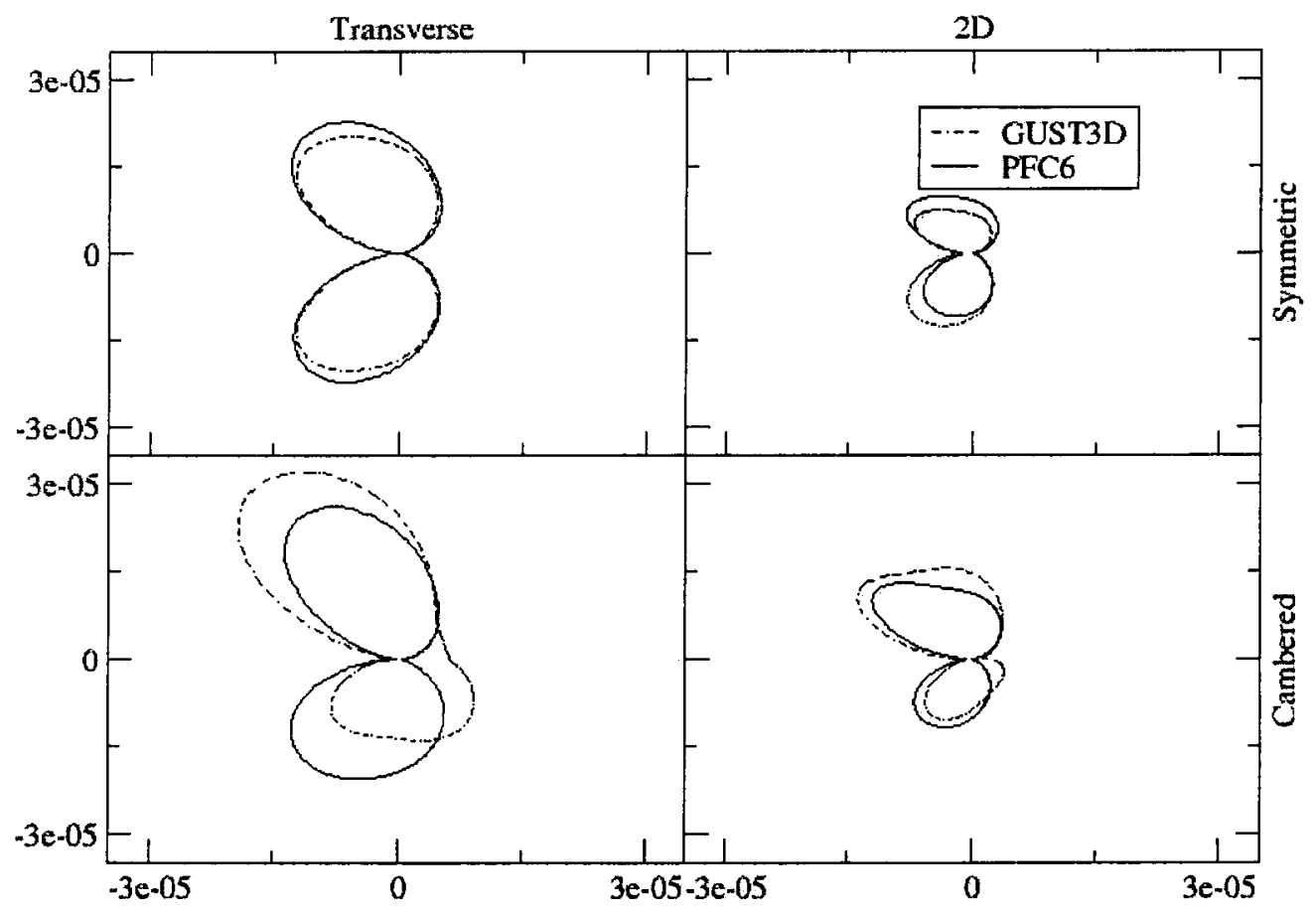

Figure 12: Acoustic Intensity Distribution at $R=1.0$

$$
(\mathbf{k}=\mathbf{1 . 0})
$$




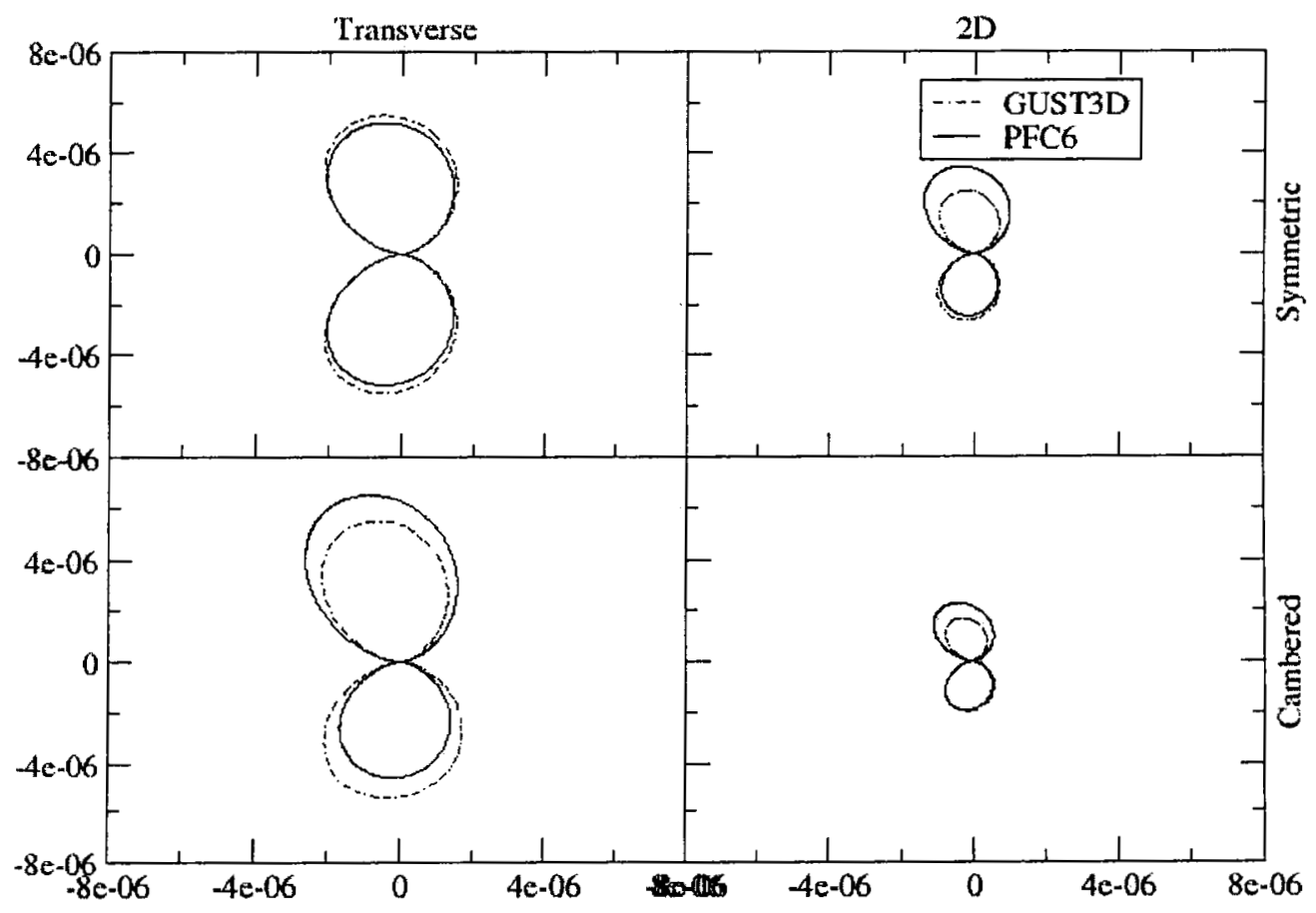

Figure 13: Acoustic Intensity Distribution at $R=4.0$

$$
(\mathrm{k}=\mathbf{0 . 1})
$$




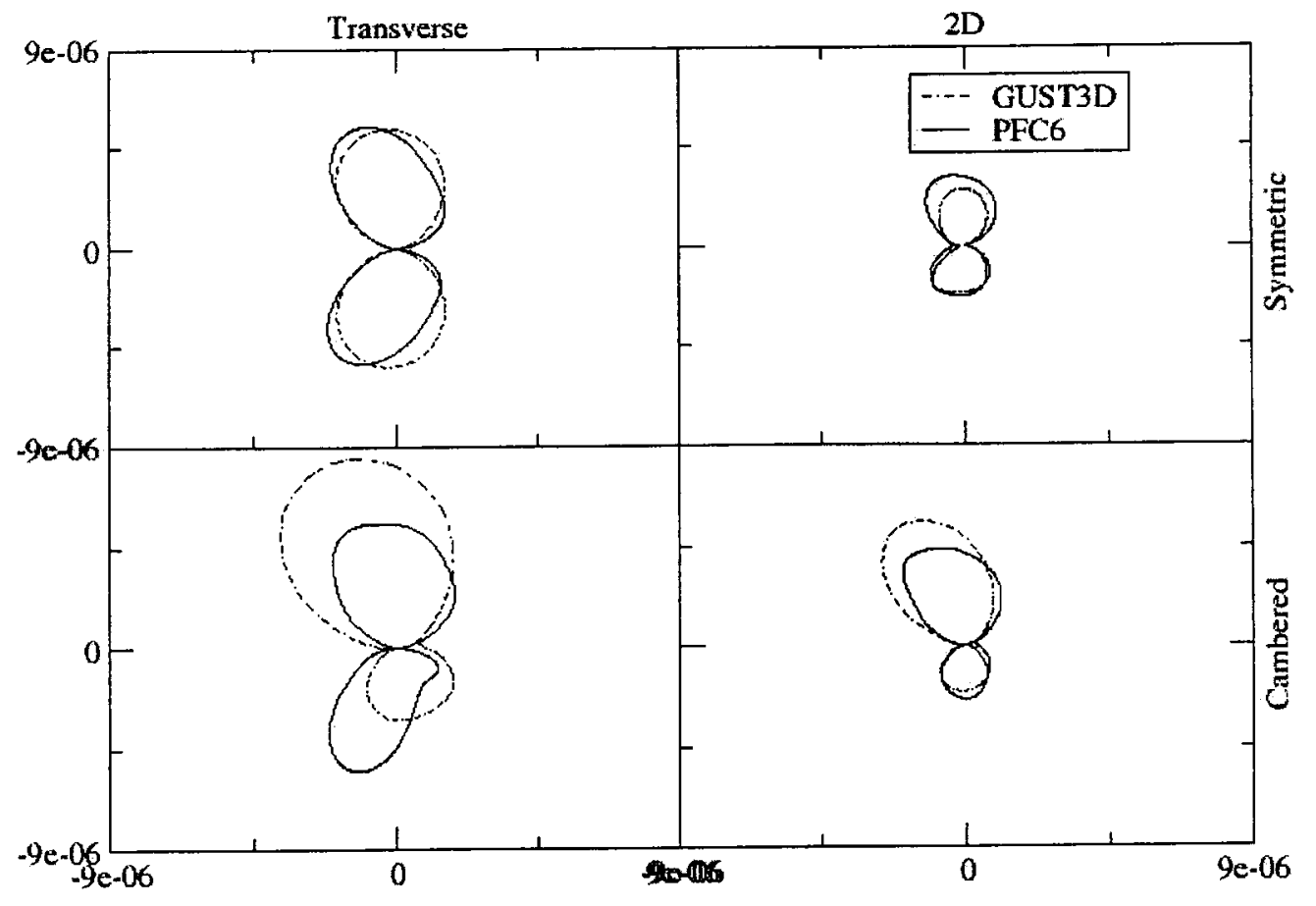

Figure 14: Acoustic Intensity Distribution at $R=4.0$

$$
(k=1.0)
$$




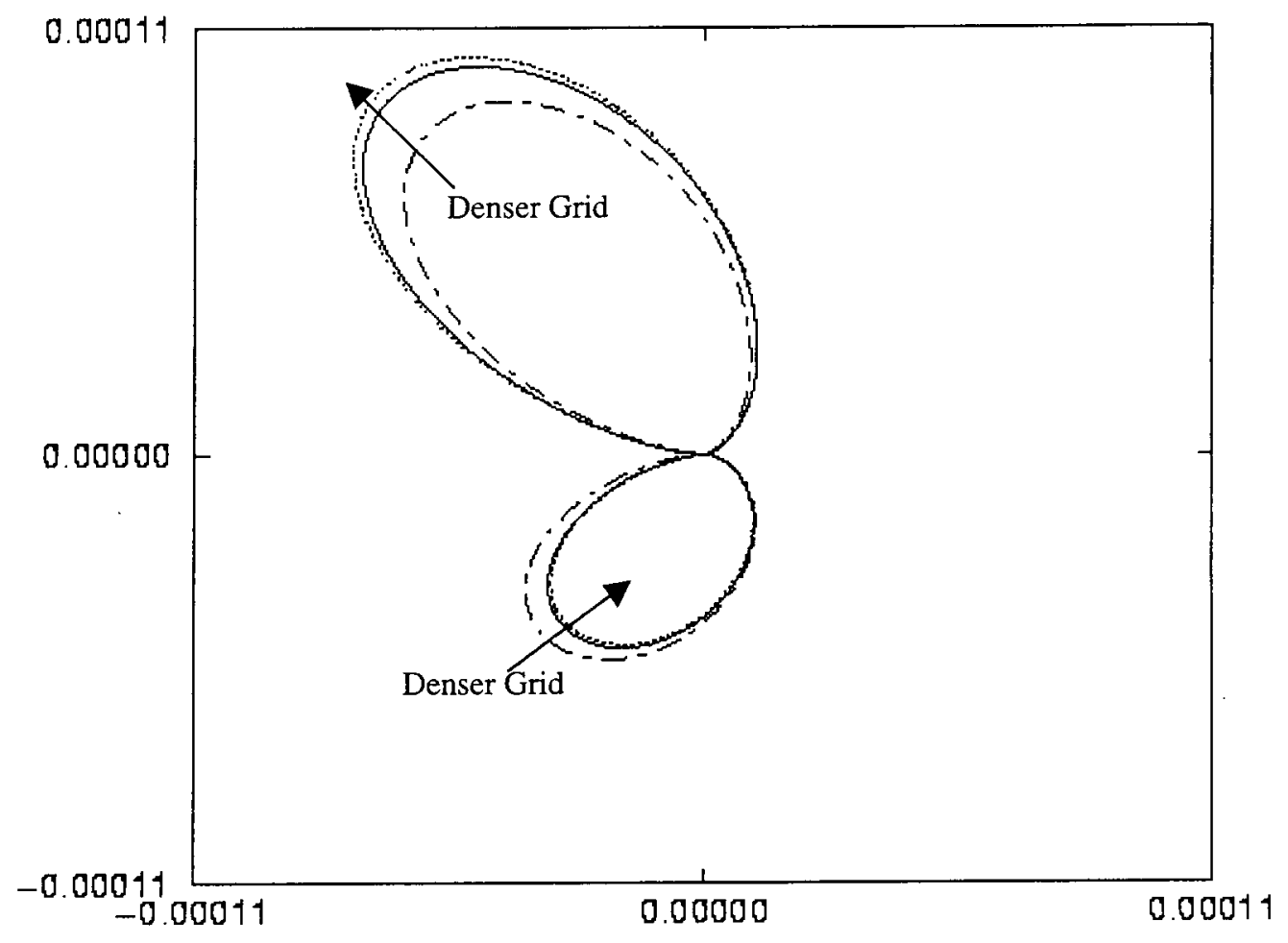

Figure 15: Effect of Grid Density on the Acoustic Intensity at $R=1.0$

$$
\text { ( } k=0.1,1 \mathrm{D} \text { gust, cambered airfoil) }
$$




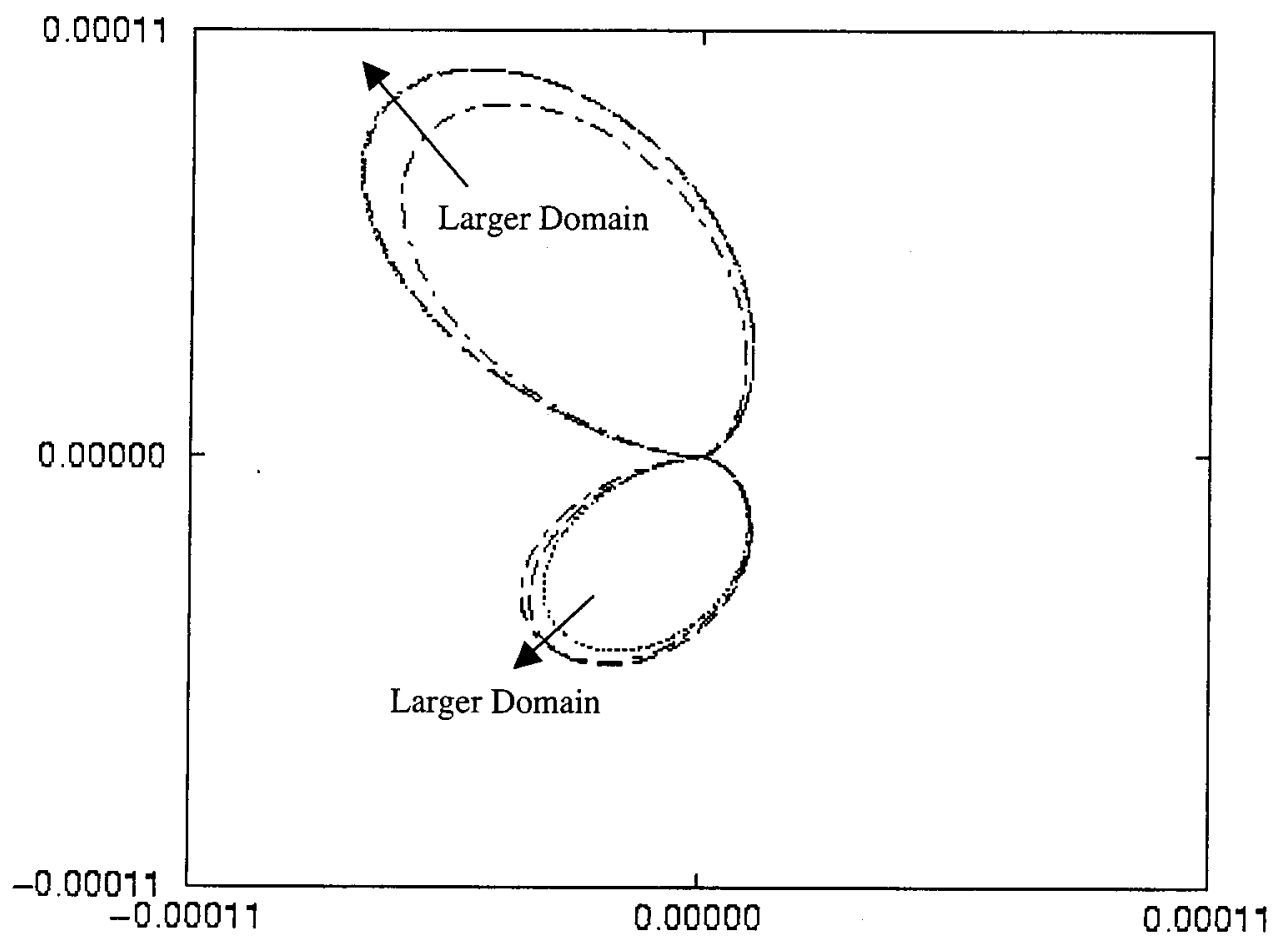

Figure 16: Effect of Domain Size on Acoustic Intensity at $R=1.0$ ( $k=0.1,1 D$ gust, cambered airfoil) 


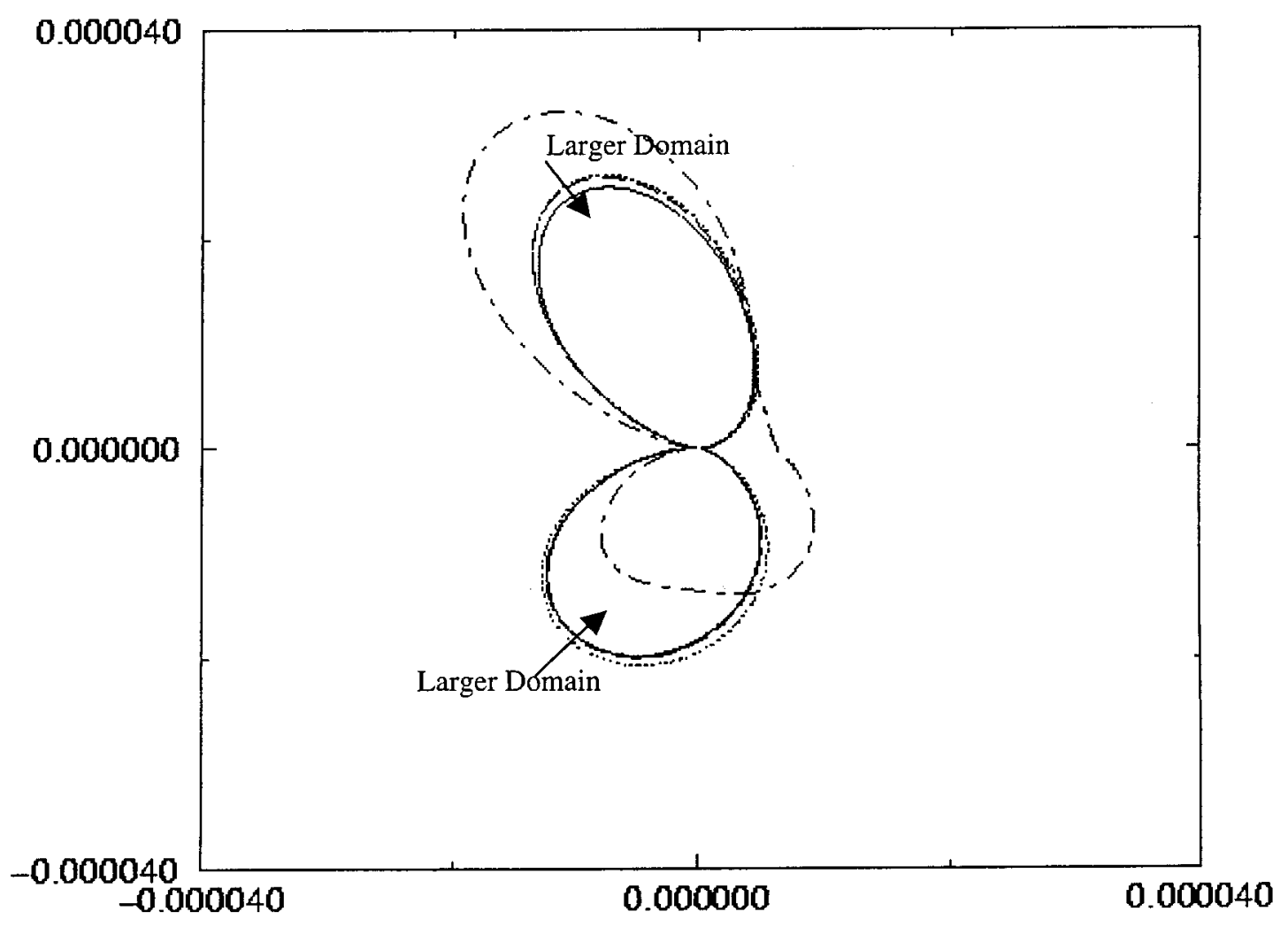

Figure 17: Effect of Domain Size on Acoustic Intensity at $R=1.0$

$$
\text { ( } k=1.0,1 D \text { gust, cambered airfoil) }
$$

